\title{
Study on Crisis Management Strategy for Universities
}

\author{
Yue Min Zhen ${ }^{1, a}$, She Hui Bian ${ }^{2, b}$ \\ ${ }^{1}$ Department of Teaching Affairs, Beijing Electronic Science and Technology Institute, Beijing, \\ China, 100071 \\ ${ }^{2}$ QianAn College, Hebei United University, Tangshan, China, 064400 \\ azhenyuemin@qq.com, bbianshehui@163.com
}

Keywords: Crisis in universities; Characteristics; Crisis management; Strategy

\begin{abstract}
Universities are now facing new challenges with their increasing level of socialization. Among these challenges, crisis management has grown to be a hot topic for the development of universities. This paper first defines crisis in universities and then analyses the existing problems of current crisis management system. An optimized strategy is proposed from three different phased for crisis management in universities, i.e. antecedent management, concurrent management and remedial management.
\end{abstract}

\section{Introduction}

As the public organization for education, universities are featured with high population density and rapid information dissemination speed. Moreover, with the increasing level of socialization, universities are facing various uncertainties and unforeseeable crisis during its development. These uncertainties and crisis will severely affect the learning and life order of teaching staff and students, or even bruise the image and reputation of universities. Therefore, it is quite necessary to include students and universities in the scope of crisis management. The awareness of crisis and strengthening of crisis management in universities is an extremely urgent task.

\section{Connotation of Crisis in Universities}

A crisis is any unexpected and catastrophic accident or event that is seen as a threat to normal order[1]. Crisis in universities are quite different from those common social crisis due to the special characteristics of universities. A common recognition and definition of crisis in universities is described as follows integrating various explanations of experts. A crisis in universities is any unexpected event that happens suddenly on the campus of university or members from the university are involved, which seriously threatens the normal order in the university and will possibly bring other negative consequences which may include anxiety and injury to members from university, damage to teaching facilities, and even risks of losing reputations. Often these events are not able to be handled effectively with the existing man power and resources.

Except for the characteristics of suddenness, urgency and occasionality for common[2], crisis in universities are different because it will attract more social attention, it will cause the university members to follow blindly and the massive may be involved[3].

\section{Existing Problems of the Current Management Strategy for Crisis in Universities.}

Crisis in universities will seriously influence the teaching and life order, bring physical or mental harm to teachers or students, or even damage the image and reputation or universities, and will bring uncertainty to the society. Study on the strategy for crisis management in China starts late and the knowledge and awareness of sudden events in universities are not enough[4]. The existing problems of crisis management strategy in universities are as follows.

Weak Awareness for Crisis Management. Analysis to previous cases of crisis treatment shows very weak crisis awareness and crisis management awareness in universities. Due to the impact of management system, focus of government departments and leading group of universities is on daily 
teaching and management work, and thus the issue of crisis management is always neglected. University staff is lack of trainings dedicated to crisis management. Subjects related to campus safety and crisis is seldom included in the existing studies of education management theories or university management theories. Although the authorities of universities may think that safety and security are of utmost importance, the reality is that much work has to be done to maintain the universities safe from the aspect of crisis management.

Lack of Crisis Management System. Crisis management in Chinese universities is a passive management mechanism and there is no crisis prevention system. When the crisis happens, this unpreparedness will result in a chaos. A temporary organization will not be established until the crisis happens and the crisis will be handled according to improper experiences and thus will lose the active position for solving the problem. When major crisis happens, there is no solution and sometimes the crisis may be covered up, or reported late or untruly. These improper reactions will result in delay of crisis treatment, increase of crisis treatment cost and even distrust between the university authority and the students.

Lack of Psychological Intervention Mechanism. Chinese universities are in transition. With more students recruited, psychological problems may occur very easily when students facing the problems of study, life and finding a job. And this sometimes causes a crisis event. When the crisis event happens, universities will fall into a panic situation and the stress reaction of students may include anxiety, fear, distrust, etc. Greater crisis may develop unless these problems can be intervened and solved timely. Faculties dedicated to psychology in Chinese universities are in shortage. Some universities have lectures about psychology, but only basic knowledge about psychological health is taught. Psychological intervention mechanism does not play its role during the crisis.

\section{Strategy for Crisis Management in Universities}

A crisis consists of both danger and opportunity. If properly managed, a danger can be turned into an opportunity. The system, as Fig.1, is established based on the analysis of existing problems and the general principles of crisis management, which will be the basis for the following strategies.

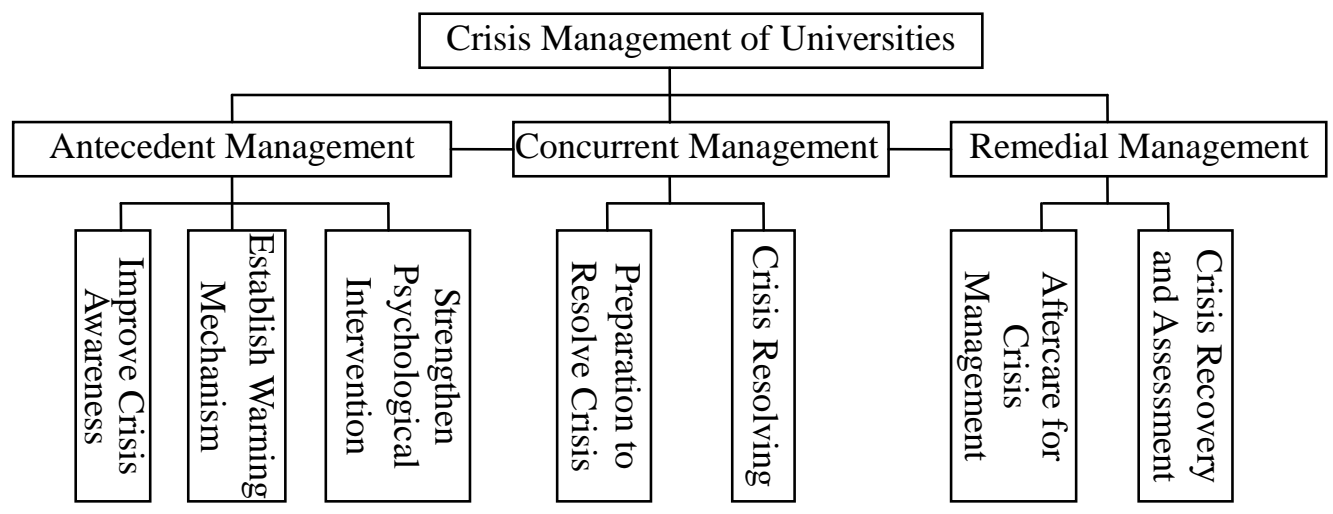

Fig. 1 Crisis Management System of Universities

Antecedent Management of Crisis in Universities: Preventing Accidents before they Occur. Increase the Crisis Awareness of Teachers and Students. Crisis awareness is the basis for crisis prevention and management, which requires alertness and action in daily management work. The leading members of universities shall learn more about crisis management and increase their awareness of crisis management. Education and training lectures dedicated to crisis management shall be organized for teachers and students. Planned and purposed crisis prevention drills shall be organized to increase their awareness and ability handling crisis. Strengthen moral education for teachers and improve the management mechanism so as to increase the management ability. The rights and benefits of teachers and students shall be attached more importance in a people-oriented 
way. Regarding the unsafe factors surrounding the campus, the universities and local government shall coordinate with each other and create a harmonious and safe surrounding for all the students and teachers.

Establish a Crisis Warning Mechanism. Crisis never happens without its starting, changing and developing. If we can prevent early and discover early, the event can be guided to a favorable direction and the crisis may be prevented. Even the crisis does happen, immediate response will minimize the negative impacts. Therefore, during daily management work, scope of work and responsibilities for each department shall be defined clearly[5]. Potential risks that will cause a crisis shall be examined regularly and measures shall be taken to prevent crisis. A special crisis management organization including school leaders, teaching department, student affairs department and logistics department shall be established to handle crisis management affairs including mechanism building and production of emergency plan. The special group shall respond as soon as the crisis happens to precisely define the properties and identify the damages of the crisis. Immediate actions shall be taken to rapidly transform the crisis management conditions.

Strengthen Daily Psychological Intervention. There shall be a systematic psychological education plan for each university. Most crises in universities are caused by minor problems which are not solved at the beginning and became psychological problems and misbehaviors. Psychological lectures shall not only teach theoretical knowledge, but also shall teach students to handle their life challenges and how to adjust themselves and how to ask for help facing difficulties. This will increase its bearing ability when facing frustrations. Dedicated psychological consultancy organization shall be established to provide psychological consultancy service according the needs of students such as service hotline, online consultancy, etc[6]. Professional psychological consultancy service will help to prevent crisis before it happens.

Concurrent Management for Crisis in Universities: Containing the Crisis from Spreading. Preparation Work to Resolve the Crisis. The special organization to handle the crisis shall respond immediately to identify the type of crisis, source of crisis, the possible spreading area and the possible damage level. Based on the information, a crisis treatment plan shall be made including information release, resources configuration, communications and the aftercare works. For this purpose, a dedicated crisis management group shall be established to handle the consultancy, information, decision making and execution work. The consultancy group will be responsible analyzing the impact of the crisis and the comments of the public to the event so as to provide suggestions to decision makers and also to avoid the image of university being damaged. The information group will be responsible, for one hand, communicate with persons influenced by the crisis, and for the other hand, inspect the site to search for information and also analyze and assess the information collected. The decision making group will be lead by leaders of the university and will be responsible for mastering the event and coordinate the different groups, and also authorize rights to the execution group. The execution group will be responsible for actions and response to the event based on current resources, and also execute the plan made by the decision making group.

Crisis Management and Resolving. When the crisis happens, attempt to cover up the truth is not the right method because rather than solve the problem, it will cause rumors and put the resolving efforts at a disadvantage position, or even the public image of the university will be damaged. The recommended method is to take all measures to isolate the crisis from spreading. And then take measures to the source of the crisis and clarify the truth so as to minimize the negative impact of the crisis. Meanwhile, solutions shall be found regarding different groups of people involved in the crisis. Victims are the persons who suffer direct or indirect loss and damage caused by the crisis event. For victims, their damage level shall be identified and requests shall be heard. Compensation shall be made according to the severity of their loss and damage. University staff: composure and internal unity is very important. A solution shall be worked out together. The cause for the crisis shall be investigated and the inadequacy of the management work and the responsible person shall be identified. Meanwhile, teachers and students shall be well communicated and let them know the truth so as to maintain internal stability. Media: when the crisis happens, facts shall be analyzed as soon as possible for the spokesman to release to the media. The content shall be the information 
concerned by the public including the situation of the event, cause of the event and the method for handling the event. The ability and the universities handling the event and the attitude shall be passed from the media to the public so as to reduce the impact. General public: when a crisis happens, the public needs sincere apologies and the information about aftermath treatment and investigation result shall be made public as soon as possible.

Remedial Management for Crisis in Universities: Transforming the Crisis into an Opportunity. Aftercare Work for the Crisis Management. Teachers and students will suffer double impact from the crisis; one is the tangible physical level such as loss and damage to life or property, the other is the intangible psychological loss. Therefore, the aftercare work shall include visits to victims of the event and their suggestions and opinions shall be treated very sincerely[7]. The benefits for the victims shall enjoy priority and their property loss shall be compensated timely. Psychological treatment measures shall be taken to the victims, witnesses and other students and teachers so as to help them recover and rebuild their psychological balance and to avoid new crisis.

After Crisis Recovery and Assessment. Recovery after crisis is an important part for the crisis management in universities. Whenever the crisis is controlled and no obvious damage will happen, the priority of work shall be given to the recovery after crisis. Positive propaganda work shall be done and a group of people shall be organized to communicate with the students to help them recover the morale and gradually recover the normal order and image of the university. Timely assessment and conclusion shall be done to learn from the crisis and consider this crisis as an opportunity to promote the crisis management work in the future. Related documents shall be recorded and a complete crisis management report shall be prepared with the purpose to increase the ability to manage crisis.

\section{References}

[1] G. Liu: Crisis Management (People's University Publications, Beijing 2013). (In Chinese)

[2] Y. Zhang: Study on Crisis Management for University (Beijing University Publications, Beijing 2008). (In Chinese)

[3] J. Yang and X.L. Chen: Characteristics Analysis and Management Strategy for Crisis in Chinese Universities in the New Age. Journal of University of Electronic Science and Technology of China. Vol.9 (2007) No.1, p.67 (In Chinese)

[4] J.Z. Yan: On Tactics of Dealing with Crisis in Colleges \& Universities. Journal of Henan University of Technology, Vol.7 (2011) No.1, p.139 (In Chinese)

[5] J. Zhu: Analysis on the Prevention Mechanism of University Crisis. Vocational Education Research, (2011) No.6, p.60 (In Chinese)

[6] L. Xu and X.M. Li: Study on the Model of Psychological Intervention in the College Campus Crisis. Journal of Guang Dong Communications Polytechnic, Vol.10 (2011) No.4, p.110 (In Chinese)

[7] X.F Zheng: The Implement of Psychological Debriefing after Crisis in University. Journal of Ningbo Institute of Education, Vol.13 (2011) No.4, p.14 (In Chinese)

[8] C.L. Wang, S.R. Wang and S.J. Cheng: Enlightenment of American University Crisis Management. Fujian Forum, (2010) No.12, p.89(In Chinese)

[9] J.H. Zhang: Crisis Management in Colleges and Universities and Countermeasures. Journal of Longdong University, Vol.24 (2013) No.1, p.96 (In Chinese)

[10]X. Tan: Coping Media and Establishing Emergency Mechanism in University Crisis. Industrial \& Science Tribune, Vol.13 (2014) No.9, p.253-255 (In Chinese) 